\title{
In Search of a Cultural Interpretation of Power: The Contribution of Pierre Bourdieu
}

\section{Zander Navarro*}

I can say that all of my thinking started from this point: how can behaviour be regulated without being the product of obedience to rules? (Bourdieu 1990a: 65)

\begin{abstract}
1 Introduction
In his book Yo El Supremo (1974), an epic narrative about the nineteenth-century dictatorship of José Gaspar Rodríguez de Francia in Paraguay (1814-40), Augusto Roa Bastos, probably the most acclaimed writer that country has ever had, wrote a passage on human interaction that is illuminating. He noted that:
\end{abstract}

Rage, no matter how justified, is something one should never tolerate in oneself. For nursing anger against someone is the same as allowing that person continued control of our thoughts, or our feelings. The least moments. That is lack of selfsovereignty. The height of stupidity in fact. (Roa Bastos 1974)

In a very different context and historical period, the weekly publication The Economist, as the selfproclaimed guardian of classical liberal doctrine in economics, published in 2005 a survey about the recent tendency of firms, in particular the largest multinationals, to promote 'corporate social responsibility' as a way of demonstrating their social concerns as being attuned with the broad public interest. In its typical ironic vein, the article insists that:

It would be a challenge to find a recent annual report of any big international company that justifies the firm's existence merely in terms of profit, rather than 'service to the community'. Such reports often talk proudly of efforts to improve society and safeguard the environment ... on the face of it, this marks a significant victory in the battle of ideas. The winners are the charities, non-governmental organisations and other elements of what is called civil society ... in public relations terms, their victory is total. In fact, their opponents never turned up. Unopposed, the CSR (corporate social responsibility) movement has distilled a widespread suspicion of capitalism into a sect of demands for action ... intellectually, at least, the corporate world has surrendered and gone over to the other side. ('A Survey of Corporate Social Responsibility' 3, The Economist, London, 22-28 January, 2005 [emphasis added])

These excerpts, taken from such contrasting historical moments and related to distant worlds, might have in fact an underlying common facet. Albeit under a different lens, both of them could refer to a political process that theorists would focus under a single word - power. 'Power is ubiquitous', some would argue (Guzzini 2000: 53; Foucault 2000), but if this is so, then its manifestations may encompass a vast variety of concrete possibilities, ranging from influence to domination or from violence to force or indeed from oppression to coercion. Does power embrace all these concrete possibilities existing in social life? Is internalised anger, as cited in the passage by Roa Bastos, a form of power exerted by someone from a distance over the mind of an individual, thus limiting one's own sovereignty? Or, on the contrary, is anger against a form of domination or power precisely the opposite, that is, a form of personal resistance against oppression by powerful opponents? On the other hand, is the influence of international aid donors and nongovernmental organisations (NGOs) on large corporate firms forcing them to adopt 'social concerns' a dimension of power, or is it something 
different? If profit, the driving force of capitalism and its ultimate raison d'être, becomes not only a secondary objective but also an embarrassing goal of firms which are nothing to boast of, then the 'victory' of NGOs is indeed total, as mentioned in the second excerpt. These examples, therefore, illustrate the difficulties of dealing with the notion of power, both analytically and in concrete situations.

In recent times, under the thrust of newly enthroned electoral democracies in so many countries, diffusion of information through enhanced means of communication, among other factors that are uncovering existing social inequalities and widespread social immiseration, power is gradually becoming a central theme society should address itself to. Processes of democratisation, in particular, are creating new spheres of conflicts, which animate citizens formerly subjugated under hidden linkages of domination to enter a brave new world of political discourse that promises to improve their lives and social conditions and, moreover, to empower them. Poor social groups, in particular, are invited, even by conservative multilateral organisations, to engage in decision-making spaces in order to voice their demands and express their grievances, to discuss them and decide on new mechanisms to solve social problems. In short, citizens are summoned to struggle for their interests or, in other words, to engage in power relations under a novel political rationale, although this was seldom the intention of the organisations that established these new spaces.

However, power is perhaps one of the most elusive notions in the social sciences and interpretations about its meanings and forms of analytical inquiry abound (Hindess 1996). Starting perhaps with the pioneering definition by Weber, ${ }^{1}$ a varied intellectual discussion on power has been developed in the postwar period, in particular after the seminal contributions by Steven Lukes (2005) and the Foucauldian collected texts (Foucault 2000) both writing from the mid-1970s to the early 1980s (Haugaard 2002), several questions remain for those interested in understanding this theme: Who has power, and how is it possible to identify them? Can power be inscribed in structures and be transformed into an impersonal force to control social order and impel individuals to act in specific trajectories? Which are the conditions that enhance (or reduce) mechanisms of power? Which are the outcomes of power that matter? Are changes of firms' attitudes, as in the example cited above, a direct result of power or represent mere influence? Can power be so dissimulated (as in the frequently quoted 'false consciousness' idea proposed by Marx) that individuals do not grasp lineages of domination and social control that limit their autonomy and scope for action? Is passivity a reflection of stronger patterns of power or can rational persuasion be achieved? If power is so crucial to interpret any given social arrangement, and thus to identify social limits and possibilities, how does one scrutinise its manifestations? Under the pressure of contemporary events, these and other related questions are urgent topics to be researched.

This article proposes two main claims as a starting point. First, it argues that a rigorous and productive discussion on power must be anchored on a broader view about social life. In other words, an understanding of power in a given context requires beforehand a 'theory of society' to avoid risking an analysis that reduces power into a variable or 'factor', a discreet and one-sided component of social reality, unconnected to existing structures, social action, and the multiple facets of social arrangements. Reasons for this requirement are straightforward: if power is so pervasive and determines the whole set of social relations and structures, then it is hardly imaginable that power can be theoretically (and concretely) understood without a broad understanding of society. It means that debates about power are sometimes flawed exactly because they are devoid of larger social determinants and thus incapable of really analysing power as a relational process that, in fact, sustains the fabric of society. Even if 'forms of power' are scrutinised, they are hinged upon a larger structure that is the ultimate reality of a given social order (Haugaard 2003). Second, this article makes a bold claim to suggest that the sociological theory proposed by Pierre Bourdieu (1930-2002) is perhaps the most promising analytical framework to understand power structures and power relations. Most competing analyses, which cannot be compared here because of lack of space, are insufficient or partial, exactly because their premises and body of concepts are not founded on an encompassing theory that explains how, after empirical research, the entire edifice of society was historically formed. ${ }^{2}$

This article is in three parts. The first is a brief overview of the general theory of social practices 
proposed by Bourdieu. The second introduces the main concepts of habitus, cultural capital (and other forms of capital) and field. The final part attempts to offer some insights about his cultural theory of power and to defend its relevance. This article does not intend to present a summary of this analytical corpus. It is obviously impossible to synthesise the vast and highly complex work of Bourdieu in a short article. After all, it has been insisted by disciples and specialists that his work cannot be summarised in a few pages (Swartz 1997; Calhoun et al. 1993). My intention is, then, merely to call attention to an ambitious and innovative theory developed in order to understand how social arrangements materialise over time in specific circumstances, hence illuminating power relations that constitute the very foundation of these arrangements. It is an invitation to read Bourdieu and experiment in concrete situations with his theory in relation to prospects for social change and human agency. Such an experiment enables one to respond to the simple but fascinating challenge he posed himself in as early as 1962 and which should be the main motto of all social analysts: 'Surely, Sociology would not be worth an hour's trouble ... if it did not give itself the job of restoring to people the meaning of their action'. ${ }^{3}$ This article thus suggests a possible route for those interested in pursuing this theoretical enterprise to understand power structures and power relations in a given context. ${ }^{4}$

To illustrate the potential explanatory utility of Bourdieu's theory, I will introduce four short boxes in this article in order to relate his concepts and ideas to concrete contextual situations experienced by the Brazilian Landless Movement (MST). This organisation represents the interests of poor landless families in many parts of Brazil and is well known for its successful history of social mobilisation and creative repertoire of struggles. Formally established in 1984, the MST has gradually moved onto the political scene in that country, especially in the last decade. It is nowadays an actor that no discussion on land reform could possibly ignore. Nevertheless, MST's history depicts an ambivalent development because whereas the number of rural settlements formed under the pressures exerted by the organisation rapidly increased, its internal structure still displays many authoritarian facets. MST, as a result, is an ideal subject for study in a complex field in which Bourdieu's theory may be appropriately applied. ${ }^{5}$

\section{An overview}

The intellectual trajectory of Bourdieu and his sociological project represent an extraordinary example of logical consistency and analytical brilliance. Perhaps the most innovative and influential social scientist in the history of French social science, his name is certainly inscribed alongside the shortlist of social thinkers who proposed models to understand society that are deemed to be part of the classical tradition in the field. He came from a modest low-income middle-class background in rural South-western France to become, perhaps, the most acclaimed social scientist in that country in contemporary times. His output is remarkable and covers a large range of sub-fields and topics. ${ }^{6}$ He has written about culture and social classes; the sociology of language; about peasant communities and social groups in Algeria; education; consumer and cultural tastes; religion and science in modern France, and even about the social aspects of French housing markets and nineteenth-century artists and writers. His theory, however, follows a clear logic of continuous evolution starting with his works in Algeria, where he conducted ethnographic studies among the Kabylia groups, and about Algerian society, a study that led to his first book, Sociologie de l'Algerie, published in 1958 (English edition, The Algerians, published in 1962).

Nevertheless, Bourdieu's vast work and ingenuous theory of society and social practices is still not properly known in the English-speaking world for various reasons. First, his initial impact there was the acclaimed Reproduction in Education, Society and Culture (English edition, 1977), which situated him as a specialist in the field of the sociology of education rather than as a more general social theorist. Second, the influences embodied in his theory and his multidisciplinary approaches are too vast and, sometimes, incorporate strands of thought that are not very well known in the social sciences dominated by the English language.?

His theoretical project was also an ambitious effort to deal with old dilemmas in the social sciences. That is, his purpose was to create a theory of social practices and human action equidistant from the opposing poles of either an overemphasis on agency or a one-sided focus on structures, but he was also trying to escape from the old epistemological disputes confronting subjectivism versus objectivism. While the first encompasses forms of knowledge 
that centre on individual or intersubjective consciousness, objectivism refers to products of knowledge that focus on statistical regularities of social conduct. Bourdieu's general theory and some of its most important concepts like habitus and field, however, clearly transcend these dilemmas. Perhaps he was one of the first major social scientists to deal with those challenges in the postwar period and to eventually offer a theory that clearly avoids those analytical impasses.

Bourdieu's work reflects the distinct and eclectic influence of classical sociology. He gains several insights from Durkheim, Marx and, in particular, from Weber. From Marx, he was inspired by the idea of social reproduction and his theory incorporates historical materialism and the idea that class conflicts and material interests are primary pillars of social inequality. Though a materialist when he links human consciousness to material life, he rejects, however, the class reductionism that is so common in Marxist discourse. He also confers a great importance on the idea of false consciousness, but refers to it as the 'misrecognition' of power relations to explain why individuals are not aware of their own subordination to powerful agents. He also incorporates the Marxian idea that symbolic systems help consolidate forms of domination. However, he refuses the idea that these are a direct result of material dimensions, in particular the unequal appropriation of wealth. Because of these caveats, he eventually rejects the opposition postulated in Marxian social analysis of infrastructure versus superstructure.

For Bourdieu, the social world can be conceptualised as a series of relatively autonomous but structurally homologous fields of production, circulation and consumption of various forms of cultural as well as material resources. He seeks to write a general theory of practices that combines both material and symbolic dimensions and thereby emphasises the fundamental unity of social life. In his view, it is ontologically incorrect to indicate ex-ante structural hierarchies concerning fields of social action (the predominance of the economy, for example) because only concrete circumstances will demonstrate their relationships.

Weber (1978) left a stronger mark on Bourdieu's writing. Like the German sociologist, he asks: 'What motivates social action? Do individuals act in response to external causes like 'culture' or 'social structures' or do they act for their own identifiable reasons? Weber answered 'yes' to the second question in relation to the study of religious behaviour; Bourdieu, on the other hand, claims that all actions in any sphere of human interaction are fundamentally 'interested' (even solidarity) whether they are directed towards material or symbolic items. He proposes a science of social practices that posits as a premise (not as a hypothesis) that all practices are oriented towards the maximisation of material or symbolic results, that is, mainly interest-motivated. Symbolic or material interests are objective forms of interest and this presupposition allows him to develop concepts such as religious capital and cultural capital as irreducible forms of power. These forms of capital can be produced under different strategies and command of resources, accumulated and exchanged with other forms of capital, including economic capital. They are resources and are transformed into capital when they function as social relations of power. They are also the mechanisms that give rise to social hierarchies, thus becoming objects of struggle as valued resources.

His starting point is, therefore, an acceptance of two basic principles of human behaviour. First, drawing on Weber (but expanding his scope), Bourdieu argues that all actions by individuals in social arrangements are interest-driven, regardless of the specificities of a given concrete context. As a result of this first premise, he maintains that while self-interest is the driving force of human behaviour, the final result is that social struggles are the main facet of social arrangements in any specific field, because individuals try to maximise their gains and accumulate resources under different forms of capital (economic, social, cultural, symbolic). The historical outcome of this persistent search for accumulation of resources is to entrench hierarchies that in their turn require a permanent vigilance to legitimise these social differences - hence a continuous effort to keep 'misrecognition' about the origins of these asymmetries. This is the reason why Bourdieu's theory is essentially political and deals with power relations as its core objective.

A second foundational principle in his theory is the notion that culture is not only the very ground for human interaction, but is also an especial terrain of domination. He argues that all symbolic systems are anchored in culture and thus determine our understanding of reality. They both ensure 
The Brazilian Landless Movement (MST), famous in its efforts to enlarge the scope of land reform in that country, has developed a series of actions that has become typical of its repertoire. After invading private land and forming a new rural settlement, if legal expropriation is later formalised, the organisation usually tries to impose on the new settlers a land and organisational pattern that consists of forming a cooperative associated with a collective use of the entire settlement, instead of implementing a mosaic of independent small private tracts of land. The MST argues that this is the only way to increase chances of the new farmers surviving in the market, benefiting from economies of scale and also being protected from the political hostile environments that sometimes surround the settlements. From a purely theoretical point of view, these guidelines may be correct. However, a Bourdieu-inspired empirical research in rural settlements would demonstrate how wrong this strategy has been in the Brazilian countryside. It would prove that the social history of poor families is one of controlling land resources and family labour not only as a mechanism to survive under difficult market conditions (that have persisted in the new rural settlements) but also as a form of maintaining patriarchal domains. That is, the private small farm is the ideal social sphere where adult men, in fact, command labour distribution, and decisions on land use, but also exert power in the domestic unit. These patterns reflect habitus, and if MST was aware of these strong roots determining social and cultural interaction in rural areas (meaning a very conservative attitude towards collective forms of production because it dissolves that domestic control), MST would not try to implement those cooperatives, at least for some time. MST's cooperatives, in most cases, have produced widespread infighting in the new rural settlements and are usually an organisational failure.

communication and interaction, but also create and maintain social hierarchies. Culture, in the form of dispositions, objects, institutions, language and so on, mediates social practices by connecting people and groups to institutionalised hierarchies. Thus it necessarily embodies power relations. Whenever a given society changes and develops through social differentiation and growing complexity, culture and symbolic systems may become relatively autonomous arenas of struggle for difference vis-à-vis other fields. This is encapsulated in the word 'distinction' which is a crucial concept (Bourdieu 1984). Thus, cultural capital in some specific concrete situations may be of immense value to perpetuate social differences and hierarchies. His studies of French society, in particular the impacts of the educational system in ensuring a rigid power distribution and the permanence of social inequalities, are one of the most brilliant contributions Bourdieu has made to sociology and what has made him recognised as a specialist in the sociology of education.

In spite of the fact that he competes with Foucault as the most cited French author in the Englishspeaking academic world, outside France the overall framework built by Bourdieu has not so far received the attention it deserves. There is even an idea that his work is too abstract and theoretical, which is a curious perception since his epistemology is necessarily grounded on empirical research. He sharply criticised theory for the sake of theory because it might emphasise abstract

conceptualisation per se, outside subjects of empirical investigation. ${ }^{8}$ The concepts he introduced are not designed to respond just to logical consistency but are forged out of empirical research. Due to this aspect, he has developed in fact, a meta-theory of social practices. As Swartz rightly asserts:

Since all symbolic forms function to general social distinction, the practice of social science itself is not exempt from the process of social differentiation. Thus, Bourdieu rejects scientific positivism and its ideal of value-neutral objectivity ... what form of objective scientific knowledge is therefore possible? ... Bourdieu insists that socioanalysis simultaneously requires reflexivity, that is, a systematic and rigorous selfcritical practice of social science ... standards of critical inquiry he applied to observing social scientists as well as to their objects of observation ... he sees a sociology of sociology as a necessary means for freeing the social scientist from the constraints of symbolic struggle in the field of science ... the practice of genuine science requires a "reflexive turn" upon itself. (Swartz 1997: 10-11 [author's emphasis])

A reflexive sociology under these lines, he claims, while uncovering sources of power and illuminating reasons that explain social asymmetries and hierarchies, offers a good chance of producing real 
knowledge about a given context and, as a result, is a powerful tool to enhance social emancipation. For this reason, Bourdieu's theory is essentially a political intervention, a form of political practice expressed as social science.

\section{Central concepts}

An erudite social scientist with a multidisciplinary formation and a solid background in philosophy, Bourdieu's creativity is remarkable. He proposes precise innovative concepts that fit specific analytical requirements to explain and interpret the different parts and theoretical relations of his model. Reasons of space determine mentioning only a few. In his book Distinction (1984: 101), for the sake of brevity, Bourdieu himself offered the widely quoted formula that highlights the main concepts and, also, their relationships:

$$
[\text { (habitus) } \quad \text { (capital) }]+\text { field }=\text { practices }
$$

Habitus, his central concept, evolved from his early studies in Algeria in the 1950s. It is an old philosophical notion going back to Aristotle; for Bourdieu it designates not only the foundational basis of practices but also the analytical objectives of circumventing the impasse of subjectivism versus objectivism. According to one of his main interpreters, habitus:

is a mediating notion that revokes the common sense duality between the individual and the social by capturing 'the internalisation of externality and the externalisation of internality' [in the famous expression of Bourdieu], that is, the way society becomes deposited in persons in the form of lasting dispositions, or trained capacities and structured propensities to think, feel, and act in determinate ways, which then guide them in their creative responses to the constraints and solicitations of their extant milieu. (Wacquant 2005: 316)

Through habitus, social practices are neither the mechanical imposition of structures nor the outcome of the free intentional pursuit of individuals. In his earlier writings, still not placing a decisive importance on the concept of field, Bourdieu would emphasise that a given practice is:

... the product of a dialectical relationship between a situation and a habitus, understood as a system of durable and transposable dispositions which, integrating all past experiences, functions at every moment as a matrix of perceptions, appreciations, and actions, and make it possible to accomplish infinitely differentiated tasks, thanks to the analogical transfer of schemata acquired in prior practice. (Bourdieu 1977: 261)

It is not a natural or merely individual trait, but a social facet, thus varying across time, place and across power distributions in different fields. It is also transferable to distinct spheres of practice and this explains its consistency when a particular social domain is observed. Yet, it is not fixed or permanent and can be changed under unexpected situations or over a long historical period. Most important, however, still following Wacquant, habitus

is endowed with built-in-inertia, insofar as habitus tends to produce practices patterned after the social structures that spawned them, and because each of its layers operates as a prism through which later experiences are filtered and subsequent strata of dispositions overlaid (thus the disproportionate weight of the schemata implanted in infancy). (Wacquant 2005: 317)

Habitus is especially developed through processes of socialisation and determines a wide range of dispositions that shape individuals in a given society. It is not a 'structure' but a durable set of dispositions that are formed, stored, recorded and exert influence to mould forms of human behaviour. It may vary in accordance to the social environment, because unstable social domains may produce unstable systems of dispositions that generate irregular patterns of action. It does reinforce cohesion but also stimulates change and innovation, especially when it does not fit the surrounding social world where it evolves.

But habitus is a necessary condition, not a sufficient one when social actions and practices are to be generated. Capital(s) is the second part of the equation orchestrated in the formula above. The idea of capital is extended to all forms of valued resources (and, as a consequence, objects of conflictive dispute and the foundation of power hierarchies), whether they are material, cultural, social, or symbolic (Bourdieu 1986). For him, resources function as capital when they are 'a social relation of power' because this is precisely what determines value upon resources after interest is manifested (and/or disputed) by people. Also crucial is the fact that none 
The history of the MST in Brazil has been one of enormous success when its political influence is considered. Why? Bourdieu would explain the rise of that organisation into the realm of Brazilian politics as a result of its increasing capacity to produce and accumulate, particularly, political capital, after devising creative forms of social mobilisation and developing new alliances with urban social sectors, not to mention many reform-minded government officers. Research inspired by Bourdieu would reveal that the MST over the last 20 years (and especially from the mid-1990s onwards) has been able to capitalise immensely on various forms of capital. It has exchanged political capital, for example, with cultural capital amassed by many intellectuals and academics in different universities in the country, thus increasing its total control of capital. Scientific authority (or 'distinction', in Bourdieu's words) brings an added 'value' to the forms of capital the MST was able to accumulate in the period of its existence. The recourse to iconic symbols, such as its now famous red flag (not to mention the caps) also increased its symbolic capital. This is a concrete social movement where the theoretical perspective introduced could produce a much better understanding on how forms of capital were developed over time and, most important, how they also created internal hierarchies inside the MST itself. A clear power structure would emerge as a result, showing internal positions and forms of domination.

of these forms of capital is a priori dominant, which represents a major rupture with Marxist theory. In fact, when making capital more equivalent to the notion of wealth than capital properly speaking, his theory misses here the theory of surplus appropriation and also of labour exploitation that is embodied, for example, in the Marxian concept of capital (Beasley-Murray 2000). Individuals mobilise resources in order to assure their position in the social order and these resources are forms of capital when they function as a social relation of power or, in other words, when resources are objects of social struggles. He usually mentions four types of capital: economic capital (money and property); cultural capital (cultural goods and services, also including educational credentials); social capital (networks and acquaintances) and symbolic capital (which refers to legitimacy).

His equalisation of the essence of forms of capital as valued resources and the rejection of economic capital as a superior form of capital appears rather ambivalent in many parts of his works but makes sense within the rationale of his general theory of practices, in particular under the conditions of advanced capitalism (where cultural capital became so prominent). One basic requirement is to highlight exactly the crucial relevance of culture as a producer of valued resources and, as a result, as a form of capital. According to him, a 'general theory of the economy of practices [requires one] ... to abandon the economic/non-economic dichotomy [which is to be replaced by] ... a science capable of treating all practices' (Bourdieu 1990a: 122; see also Bourdieu
1986). Being exchangeable, capitals for him assume different forms and originate in various fields structuring a concrete social order and, as a result, it is possible to locate them empirically and interpret how accumulation of different forms of capital creates distinct forms of hierarchies and volumes of power. This fluidity in exchanging forms of capital is visually demonstrated in his well-known chart introduced in the book Distinction where he exemplifies how particular agents (people or groups) may command differing absolute stocks of capital (under its different forms), which will make up varying proportions and a resulting positional field (Bourdieu 1984: 128-9). ${ }^{9}$

The third core concept is field. This is a more recent concept in Bourdieu's writings. It is especially discussed in his work of the 1980s and seems to add a greater complexity to his theory. $\mathrm{A}$ field delimits a structure in which habitus operates. Bourdieu proposed a standard definition of field as

... a network, or configuration, of objective relations between positions. These positions are objectively defined, in their existence and in the determinations they impose upon their occupants, agents or institutions, by their present and potential situation (situs) in the structure of the distribution of species of power (or capital) whose possession commands access to the specific profits that are at stake in the field, as well as by their objective relation to other positions. (Wacquant and Bourdieu 1992: 97) 
As a result of increasing urbanisation and the growing importance of agribusiness for the Brazilian economy, in recent years the MST has experienced political difficulties to redefine its political agenda. As a result, it has embarked on controversial actions in risky new 'fields'. For example, forced by its overemphasis on anti-systemic ideology, it has developed a series of actions in order to criticise GMOs (genetically modified organisms) under a public banner of 'agroecological agriculture' when, in fact, the disguised objective is to attack multinationals producing those seeds and ultimately, to denounce 'imperialism' and the like. This mixture of fields, however, has not produced effective political results for the MST so far, especially because it has been unable to differentiate between the main facets of different fields and how they interrelate, and has also failed to grasp possible convergences and social and political barriers among these new fields. GMO research, for example, strongly involves research in natural science and the MST has usually found more resistance than sympathy when trying to combat GMOs with agents who are typical members of that field of science. In order to better define its political strategy, Bourdieu would be quite helpful here, because his theory could provide a clearer understanding about the main characteristic of those fields with which the MST is in sustained interaction.

Fields, therefore, represent a certain distribution structure of some types of capital and they indicate arenas of struggle around production, accumulation, circulation and possession of goods, services, knowledge, or status and the competition among agents to monopolise distinct capitals. They may be thought of as structured spaces that are organised around specific types of capital or combinations of capital. Bourdieu discusses various fields, like the intellectual, religious, educational, cultural, and so on. His work from the mid-1980s onwards includes a series of efforts to analyse diverse fields based on rigorous and detailed empirical research conducted by him and several researchers associated with his academic enterprise. ${ }^{10}$

However, his analytical framework is more complex and there are also many other concepts that are crucial to produce a complete intelligibility of the model. Given space limitations, they are not mentioned in this article. In his discussion about fields, for example, which resonates with his set of premises about social action, the most decisive one is precisely the field of power. Power is present in all fields but Bourdieu argues that there is a specific field of power, in two usages: as a 'meta-field' that organises differentiation and struggles through all fields and, second, it also represents the dominant class. Since he considers that conflict is the fundamental dynamic of social life, at the heart of all social arrangements is the struggle for power - not only over material resources but also over symbolic power. The study of the field of power is, as a result, crucial to unearth a clear interpretation about the origin, the meaning and the consequences of power and power relations in any specific society."

\section{Towards a cultural theory of power that promotes social change}

In a historical time when superficiality and uncritical thinking appears to dominate a good number of proposed analytical frameworks, Bourdieu's work may be seen to be at odds with these recent trends. He requires deeper empirical research and to be made intelligible, his theory does not accept partial data collection in order to understand and explain social realities. He did not develop a formal and total theoretical model that was only waiting to be applied in the field like a tool kit. On the contrary, he proposed a meta-theory that requires continuous adjustment to empirical conditions and, in some parts of his writings one does not always find precise recommendations in methodological terms. His ideas on fields, for example, were left with many specific inconsistencies. Only to illustrate these difficulties, he forcefully demonstrates that fields are arenas of struggles for control over valued resources that structure dominant and subordinate positions based on types and amounts of capital and, as a result, it imposes on agents several specific forms of struggle. This means that fields are logically structured to a significant extent by their own internal mechanisms and are relatively autonomous from external domains. But Bourdieu is not clear, for example, about hierarchies of fields and he insists that it is not possible to establish a universal classification system connecting the various fields. This is a clear contrast, for example, with grand theories (like Marxism) that claim to have discovered the laws of trans-historical processes, like capitalism.

Bold analytical models like the one Bourdieu has been developing for a period of almost 50 years are 
An ambitious research programme based on Bourdieu and applied to rural social movements in Brazil, and the MST in particular, would reveal crucial findings and could produce truly emancipatory knowledge. Again focusing on the history of the landless movement, for example, it would produce evidence of how much the MST has been successful in uncovering misrecognition rooted in class relations in Brazilian rural areas and, as a result, how it has produced greater political chances for the rural poor to resist domination. Passive subordination is so deeply embedded in relations of social domination commanded especially by the landed elites that became naturalised under culture and social practices, but the MST has bravely fought to demolish this age-old structure of power over poor rural families. However, since habitus manifestations are so deeply ingrained, these findings would additionally demonstrate that social transformation and a reversal of power relations is, in fact, a political project much more challenging than the usual promises made by the MST leadership. But the same research effort would prove, on the other hand, that the MST itself is creating new forms of misrecognition within its rank-and-file when it imposes a quasi-military and non-democratic form of internal organisation inspired by Leninist canons which, in fact, ultimately undermines the political emancipation of those poor families recruited by the MST. That is the reason why the theoretical perspective proposed by Bourdieu is so promising and relevant: it does not accept a priori compromises with social realities and openly rejects teleological premises. But it is not neutral either, for it seeks to decipher power asymmetries (and thus to indicate the forms of combating them) and there is not any preliminary political connivance with existing social practices, let alone ideological models. Rigorously based on empirical realities, his model is perhaps best equipped to produce truth about social processes than any other framework sociology has developed so far.

both a vital source for a coherent interpretation of given social groups or communities, and for demonstrating the practical utility of theory to promote social change and justice. His theory is essentially a path to unearth hidden power mechanisms of social domination, illuminate hierarchies and their reasons of existence, denounce patterns of accumulation of resources, and demystify forms of ideological justification. If a research programme is made possible in a given social order (a nation or specific social groups) so that the forms and structures generated by habitus are researched, forms of capital and their distribution are demonstrated and the constitution of fields are presented, then to understand society beyond superficial claims becomes a real possibility. Based on this knowledge, human agency is surely enhanced and political possibilities are also made more intelligible. Crossley (2002), for example, has proposed that the theory of practices of Bourdieu can be perhaps the best solution to address so many of the problems that social theorists encounter when discussing social movements.

Perhaps equally crucial is the analysis proposed by Bourdieu that uncovers those 'public transcripts' (Scott 1990) that he called misrecognition, that is, the symbolic violence of the most powerful groups that allows the naturalisation of domination, thus creating passivity and conformity to a given social order. Misrecognition expresses 'the representations of legitimacy [that make possible] the exercise of power' (Bourdieu and Passeron 1977: 5). This symbolic power is the very foundation of dominance exerted by social classes and might be immediately associated with the Marxian concept of ideology. Symbolic systems play this function, Bourdieu ponders, but he also insists that, contrary to the Marxist tradition, misrecognition embodies a set of active social processes that anchor taken-for-granted assumptions into the realm of social life and, crucially, that they are born in the midst of culture. All forms of power require legitimacy and culture is the battleground where this conformity is disputed and eventually materialises amongst agents, thus creating social differences and unequal structures. Resources and activities are transformed into symbolic power (or legitimacy) when they are separated from material interests and go unrecognised by other social groups, and when they are presented as disinterested forms of resources and activities. When this moment is reached, the origins of social inequalities become part of a mystifying discourse. After their public exposure, however, their legitimacy will be destroyed and open paths to alternating social formats will be available at the free decision of citizens. This is how sociology may become an instrument of social struggle, capable of offering freedom instead of chains of domination. 
A cultural theory of power, therefore, following the analytical possibilities offered in the model of Bourdieu, is a promising tool to illuminate society as it really is, in its ensemble of multiple forms of human interaction, and to reveal the foundational premises of any social order. Critical thought is the path this theory requires and, as such, it may become a 'solvent of doxa', in the revealing expression of Wacquant.12 For him, theories like the one Bourdieu proposed enhance human liberation, because it allows critical thought about society 'to perpetually question the obviousness and the very frames of civic debate so as to give ourselves a chance to think the world, rather than being thought by it, to take apart and understand its mechanisms, and thus to reappropriate it intellectually and materially' (Wacquant 2004: 101). If such knowledge becomes a possession of subordinate groups, it may produce social change and create the possibilities of more equal social arrangements.

\section{Conclusions}

In the face of the extraordinary complexity and brilliance of his theoretical model about the genesis and positional distribution of social practices, this article offers a brief and rather schematic view of the sociology of Pierre Bourdieu, highlighting the

\section{Notes}

* I am thankful to Márcia Hoppe Navarro and, in particular, to Rosalind Eyben, for their comments on an earlier version of this article, and to Odaci Luis Coradini for teaching me how to read and understand the sociology of Pierre Bourdieu.

1 For Weber, power refers to 'the probability that one actor in a social relationship will be in a position to carry out his/her will despite resistance, regardless of the basis on which this probability rests' (Weber 1978: 53).

2 It means that the sociological interpretation offered by Bourdieu is in line with the tradition of theories stemming from classical discourse. Like Durkheim or Parsons, his project was also to build a theory of society and a resulting sociological perspective. He distances himself, however, from the tradition of 'grand theories', especially because the latter is a tradition that builds reasoning only in abstract terms and is not rooted in empirical realities. Since this is a prerequisite of Bourdieu's analytical framework, he in fact is proposing a meta-theory of social arrangements. location of power within it. As one of the most influential, productive and creative interpreters of social life, Bourdieu cannot be summarised in brief commentaries, and this article risks being not only blatantly superficial but also risks misunderstandings about the theory proposed by him. It must be understood, therefore, as much more an appeal to readers.

If rigorously applied to concrete realities, Bourdieu's model uncovers the nature of power relations and their social basis. Through emancipatory knowledge, power asymmetries might be the subject of action by those who object to social inequalities promoted and secured by the most powerful groups in society. Social struggles may then ensue, thus forcing change and a redistribution of power. As a famous literary dialogue illustrates, power is not only a question of wording, but it is a question of who commands it:

'When I use a word', Humpty Dumpty said, in rather a scornful tone, 'it means just what I choose it to mean - neither more nor less'. 'The question is this', said Alice, 'whether you can make words mean so many different things'. 'The question is' said Humpty Dumpty, 'who is to be master - that's all'. (Carroll 1872, reprinted 1998 [author's emphasis])

3 This quotation appears as the epigraph in the seminal book about Bourdieu by Grenfell (2004).

4 The work of Pierre Bourdieu spans approximately 45 years of impressive and continuous production. He wrote more than 30 books and almost 400 articles; a good part of them in collaboration. Most of his main output has now been translated into English. They are not cited in this short article, with the exception of those that are the most essential to understand his main theory and that are published in English. A complete list of works written by Bourdieu or co-authored by him may be found at www.iup.uni-linz.ac.at/lxe/sektktf/bb/ HyperBourdieu.html (accessed 13 July 2006).

5 For a comprehensive analysis about the MST, see Branford and Rocha (2002) and Navarro (2006).

6 A sensible suggestion to understand Bourdieu's general theory of social practices and his reflexive sociology is to use a good interpretation, as the first step to overcoming the problems of an initial reading. The best introduction to Bourdieu in the English-speaking world is Swartz (1997) but Jenkins (1992) and Grenfell (2004) are also very 
good introductory texts. See also Webb et al. (2002), Calhoun et al. (1993) and Grenfell and Kelly (1999) for complementary readings. A second step would be to immerse oneself in the excellent book Loïc Wacquant wrote with the collaboration of Bourdieu himself (Wacquant and Bourdieu 1992). A third step would be to confront Bourdieu directly in his main texts (see the suggestion at the end).

7 Perhaps a third reason that explains his still limited influence in Anglo-Saxon social sciences is his style of writing which is quite different from those prevailing in English-speaking literature and, also, the fact that the majority of his books were translated into English only recently.

8 For him, for example, philosophy is an 'idealtypical form' of symbolic violence that claims to be universal and independent of social contexts. Bourdieu consistently criticises all forms of intellectual practice for the sake of abstract knowledge precisely because they are not socially constructed (Bourdieu 1983).

9 Cultural capital was the concept initially proposed by Bourdieu that became immediately famous and widely cited, allowing him to extend the logic of economic analysis to non-economic goods and

\section{Bibliography}

Beasley-Murray, Jon (2000) 'Value and Capital in Bourdieu and Marx', in Nicholas Brown, and Imre Szeman (eds), Pierre Bourdieu: Fieldwork in Culture, Lanham MD: Rowman and Littlefield; 100-19

Branford, Sue and Rocha, Jan (2002) Cutting the Wire. The Story of the Landless Movement in Brazil, London: Latin American Bureau

Bourdieu, Pierre (2005) The Social Structures of the Economy, Cambridge: Polity Press

Bourdieu, Pierre (1998) Practical Reason, Cambridge: Polity Press

Bourdieu, Pierre (1990a) In Other Words. Essays Towards a Reflexive Sociology, Stanford: Stanford University Press

Bourdieu, Pierre (1990b) The Logic of Practice, Stanford: Stanford University Press

Bourdieu, Pierre (1986), 'The Forms of Capital', in J.G. Richardson (ed.) Handbook of Theory and Research for the Sociology of Education, New York: Greenwood Press: 241-58

Bourdieu, Pierre (1984) Distinction: A Social Critique of Judgement of Taste, Cambridge, MA: Harvard University Press services. It covers a variety of resources, including verbal capacity, aesthetic preferences, educational credentials, social class attributes, types of expertise, and so on and so forth. There are numerous illustrations in his works about indicators of this form of capital. However, the extensive use of cultural capital per se also produced a neglect of his general theory of practices, which became largely misunderstood or misapprehended to date.

10 Check, for example, his studies about the housing market (Bourdieu 2005), among other empirical analyses.

11 Most probably, the best order of reading Bourdieu, if only books are considered, is to start with his works about the Algerian peasants (Bourdieu 1962) and then jump to one of his main books, The Logic of Practice (Bourdieu 1990b), followed by a short but revealing book, Practical Reason (Bourdieu 1998). Then his foundational book Outline of a Theory of Practice (Bourdieu 1977) would be better understood. After these readings, this general theory of practices would be firmly grasped and reading could then proceed with his empirical research centred on specific fields.

12 Roughly speaking, doxa means common sense.
Bourdieu, Pierre (1983) 'The Philosophical Establishment', in A. Montefiore (ed.), Philosophy in France Today, Cambridge: Cambridge University Press: 1-8

Bourdieu, Pierre (1977) Outline of a Theory of Practice, Cambridge: Cambridge University Press

Bourdieu, Pierre (1962) The Algerians, Boston: Beacon Press

Bourdieu, Pierre and Passeron, Jean-Claude (1977) Reproduction in Education, Society and Culture, London: Sage

Calhoun, Craig, LiPuma, Edward and Postone, Moishe (eds) (1993) Bourdieu. Critical Perspectives, Chicago: Chicago University Press

Carroll, Lewis (1872, reprinted 1998) Alice's Adventures in Wonderland and Through the Looking Glass and What Alice Found There, Oxford: Oxford University Press: 190

Crossley, Nick (2002) Making Sense of Social Movements, Buckingham: Open University Press

Foucault, Michel (2000) Michel Foucault: Power, New York: The New Press

Grenfell, Michael (2004) Pierre Bourdieu. Agent Provocateur, London: Continuum 
Grenfell, Michael and Kelly, Michael (eds) (1999) Pierre Bourdieu: Language, Culture and Education, Oxford: Peter Land

Guzzini, Stefano (2000) 'The Use and Misuse of Power Analysis in International Theory', in Ronen Polan (ed.), Global Political Economy. Contemporary Theories, London: Routledge: 53-66

Haugaard, Mark (2003), 'Reflections on Seven Ways of Creating Power', European Journal of Social Theory, 6.1: 87-113

Haugaard, Mark (ed.) (2002) Power: a Reader, Manchester: Manchester University Press

Hindess, Barry (1996) Discourses of Power: From Hobbes to Foucault, Oxford: Blackwell

Jenkins, R. (1992) Key Sociologists: Pierre Bourdieu, London: Routledge

Lukes, Steven (2005) Power. A Radical View, 2nd edn, Basingstoke: Palgrave

Navarro, Zander (2006) 'Mobilization without Emancipation. The Landless Movement in Brazil', in Boaventura de Sousa Santos (ed.), Another Production is Possible. Beyond the Capitalist Canon, London: Verso Books
Roa Bastos, Augusto (1974) Yo El Supremo, Buenos Aires: Siglo Veintiuno Editores: 193 (English edition, I, The Supreme, London: Faber and Faber 1987: 178). Scott, James (1990) Domination and the Art of Resistance. The Hidden Transcripts of Subordinate Groups, New Haven: Yale University Press

Swartz, David (1997) Culture and Power. The Sociology of Pierre Bourdieu, Chicago: The University of Chicago Press

Wacquant, Loïc (2005) 'Habitus', in Jens Becket and Zafirovski Milan (eds), International Encyclopedia of Economic Sociology, London: Routledge

Wacquant, Loïc (2004) 'Critical Thought as Solvent of Doxa', Constellations 11.1: 97-101

Wacquant, Loïc and Bourdieu, Pierre (1992) An Invitation to Reflexive Sociology, Chicago: Chicago University Press

Webb, Jen, Schirato, Tony and Danaher, Geoff (2002) Understanding Bourdieu, London: Sage Weber, Max (1978) Economy and Society, Berkeley: University of California Press (2 vols) 